\title{
STRATEGIC MANAGEMENT AND MULTIPLIER EFFECT
}

\author{
Milan Jemelka, Bronislav Chramcov
}
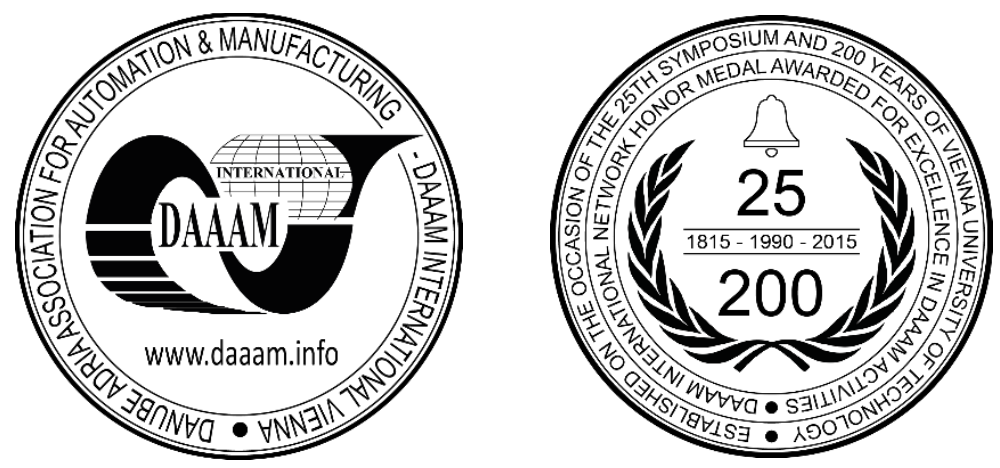

This Publication has to be referred as: Jemelka, M[ilan] \& Chramcov, B[ronislav] (2017). Strategic Management and Multiplier Effect, Proceedings of the 28th DAAAM International Symposium, pp.0704-0707, B. Katalinic (Ed.), Published by DAAAM International, ISBN 978-3-902734-11-2, ISSN 1726-9679, Vienna, Austria DOI: $10.2507 / 28$ th.daaam.proceedings.099

\begin{abstract}
Many companies are addressing the low performance of individual employees. Management of multiple companies intend to prepare individual coaching programs for employee development. Before going into this work, on one side it is the development and improvement of the employees' results, but the other side is the overall strategic management of the company and the related set of rules within the company that often influences this performance. The company's overall analysis should be conducted and the results subsequently confirm these assumptions. Human mistakes account for a maximum of $15 \%$ on the causes of problems in the company and unsatisfactory results. $85 \%$ of mistakes come from a poorly configured system, a lack of strategic management. This thesis is properly simulated in the program Witness from Lanner group. In this paper, we are concerned with discovering bottlenecks in production and with the multiplier effect aimed at increasing production. All simulation results are presented and explained.
\end{abstract}

Keywords: Simulation tool; Simulation; Witness program; Employee performance; Strategic management; Multiplier effect

\section{Introduction}

Qualified employees have recently become scarce goods. The economy is doing well, and one who's smart usually has a job or has so many offers to choose from, rather than choosing a company to accept or not. Personality politics can no longer be approached by a style in which simply those who do not suit, the company will throw away and accept new powers instead [1, 2, 3]. Looking for new talents is currently difficult. Companies need to work better with what they have, but how do we work to improve the performance of existing workers? Many companies deal with low performance of individual workers $[4,5,6]$.

Companies want to prepare individual coaching programs for employee development. Before going into this work, on one side it is the development and improvement of the employees' results, but on the other side is the overall strategic management of the company and the related set of rules within the company that often influences this performance [7, 8, 9].

The company's overall analysis should be conducted and the results subsequently confirm these assumptions. Human mistakes account for a maximum of $15 \%$ on the causes of problems in the company and unsatisfactory results. $85 \%$ of mistakes come from a poorly configured system, a lack of strategic management $[10,11,12]$. 
It is recommended in companies dealing primarily business model, how are the company's overall settings such as a strategy to win the market. Only then it is advisable to address the performance of people. If the strategy and business model are improved, which are undersized, it will bring multiplier effect in all aspects. If an undersized area of low employee performance is developed, it brings only some minor partial successes, but at the expense of disproportionately great effort $[13,14,15]$.

The price-to-performance ratio is completely unmatched. That's why it is recommend working in the first place on the strategy and setting of the whole company. If the system is well set up, it will automatically lead to better performances of existing workers even though they are not a source of improvement $[16,17,18]$.

In this paper, we are concerned with discovering bottlenecks in production process and with the multiplier effect aimed at increasing production $[19,20,21]$.

\section{Problem formulation}

An inefficient overall strategic management of the company can have a negative effect on business performance. The two main variables, which every company's performance is based are the production machines and employees. It is very common that the company's management puts a lot of pressure on the employees to make the company more successful.

However, this pressure brings only little success. The greatest success is the identification of critical locations in production, production processes and the consequent streamlining of these processes. This approach brings a multiplier effect in the manufacturing company. The limitations of the study are those characteristics of design or methodology that impacted or influenced the interpretation of the findings from our research.

\subsection{Description of current manufacturing company}

The factory produces rollers in bearings. At the input of the factory, the purchased raw material is delivered. This purchased raw material is a steel rod. This material is stored in the warehouse. From this warehouse, it is transported to two saws, where it is cut into several pieces. The subsequent cut pieces are transferred to the coater for further processing.

This is the subject of an inspection. Good production pieces continue to the hardener. Unsuitable pieces are sent back for rework. All the hardener pieces then continue to the grinder. The grinder output goes into the intermediate storage from which the material is transferred to the final workplace cleaner.

- The simulation time is always 432000 minutes. The warm up period is 550 minutes.

- The initial production of the factory is 8056 units.

- The initial workload of a machine operator is $22 \%$ of time busy and the rest idle. Number of jobs is 6066 .

\begin{tabular}{|l|r|r|l|r|}
\hline Statistics in \% & Blocked & \multicolumn{1}{l|}{ Busy } & \multicolumn{1}{l|}{ Idle } & \multicolumn{1}{l|}{ Broken } \\
\hline Saw 1 & 97,47 & 1,12 & 0,00 & 1,41 \\
\hline Saw 2 & 97,46 & 1,13 & 0,00 & 1,41 \\
\hline Coater & 76,11 & 23,32 & 0,37 & 0,20 \\
\hline Inspect & 43,36 & 49,77 & 4,45 & 2,42 \\
\hline Hardener & 64,37 & 35,39 & 0,24 & 0,00 \\
\hline Grinder 1 & 88,89 & 8,20 & 0,38 & 2,53 \\
\hline Grinder 2 & 87,26 & 9,36 & 0,40 & 2,98 \\
\hline Cleaner & 0,00 & 84,01 & 0,00 & 15,99 \\
\hline
\end{tabular}

Table 1. Overall statistics of default production machines

\subsection{Employee pressure strategy}

Most companies erroneously increase the pressure on employees instead of looking for and removing bottlenecks in production. This step simulates an increase in the performance of the operator and measure the final production of the factory.

As proof of our thesis of employers' unnecessary pressure on individual workers, we increase the workforce and performance by $20 \%$. The new production of the factory is 8322 units. The measured impact on total production growth is only $3,3 \%$. From these figures is obvious, this approach does not produce the expected result. 


\subsection{Improving the efficiency of processes and strategies}

It is very important to thoroughly examine all workplaces and then improve workflow. In the first step, it is important to find narrow places in the production process. From the table above, you can see how the workplaces follow each other. First, it is important to focus on the workplaces that are the busiest. The busiest workplace is the cleaner. In this case, it is recommended to purchase another cleaner.

In the second step, it is important to solve the blocked manufacturing machines. The least used manufacturing machines are the saws. They are blocked most of the time. According to the small use of the saws, we recommend using only one production saw device, and the other device either not to use or sell.

The last place of our focus is the inspection. There is blocking between coaters and inspections. Therefore, we recommend increasing the storage space three times between these two workplaces.

All these solutions are an attempt to find a harmonious tuning between the workplace and the achievement of a better production solution.

As part of these changes, we have increased the production of the entire plant to 15466 units. All these manufacturing changes bring up a better solution by $91,98 \%$.

The new workload of a machine operator is $42,69 \%$ of time busy and the rest idle. Number of jobs is 11666 . The multiplier effect is almost doubled compared to the default status for the machine operator. Measured improvement in percent for the operator, new value is $92,32 \%$.

\begin{tabular}{|l|r|r|r|r|}
\hline Statistics in $\%$ & Blocked & \multicolumn{1}{l|}{ Busy } & \multicolumn{1}{l|}{ Idle } & Broken \\
\hline Saw 1 & 88,27 & 4,30 & 0,00 & 7,43 \\
\hline Saw 2 & \multicolumn{1}{|c|}{ NA } & NA & NA & NA \\
\hline Coater & 52,66 & 44,77 & 2,20 & 0,37 \\
\hline Inspect & 0,05 & 95,50 & 0,00 & 4,45 \\
\hline Hardener & 0,24 & 97,14 & 2,62 & 0,00 \\
\hline Grinder 1 & 3,40 & 15,68 & 76,04 & 4,88 \\
\hline Grinder 2 & 3,25 & 17,92 & 73,17 & 5,66 \\
\hline Cleaner 1 & 0,00 & 80,62 & 1,36 & 18,02 \\
\hline Cleaner 2 & 0,00 & 80,68 & 1,42 & 17,90 \\
\hline
\end{tabular}

Table 2. Overall statistics of production machines with new configuration

\subsection{Improving the efficiency of processes and strategies and Employee pressure strategy}

Following the improved model, we have once again applied a strategy of increased pressure on employees. Manufacturing changes and increase in employee's performance about 10\% brought up production of 15961 units. The improvement is only $3,20 \%$ better, then the previous one.

\section{Analyses and results}

In the first step, it is explained that the pressure on staff alone does not produce the expected outcome. Profit in this case is not proportional to the energy consumed.

In the second step, improvements are made to individual processes and machine settings. This approach brings great improvement to the production process.

In the third step, there is an increase in pressure on employees with an efficient production configuration. Another benefit is very small.

\begin{tabular}{|r|r|}
\hline Scenario & Production in units \\
\hline Default model & 8056 \\
\hline 1. Employee pressure strategy & 8322 \\
\hline 2. Improving the efficiency of processes and strategies & 15466 \\
\hline $\begin{array}{l}\text { Improving the efficiency of processes and strategies and Employee pressure } \\
\text { strategy }\end{array}$ & 15961 \\
\hline
\end{tabular}

Table 3. Overall review of analyses and results

It's more than clear from the model that the right strategy is to focus on improving processes at the factory. 


\section{Conclusion}

The aim of the article is to demonstrate on a simple functional model, that explain the problem of the pressure on employees is not bringing any significant improvements. In the subsequent simulations, we solved it by the computer simulations, that the correct way is to focus on individual processes in the production company and harmonize them. This is the result of the article. As proof of our thesis of employers' unnecessary pressure on individual workers, we increase the workforce and performance by $20 \%$. The new production of the factory is 8322 units. The measured impact on total production growth is only $3,3 \%$. From these figures is obvious, this approach does not produce the expected result.The change of the factory strategy changed the results vigorously. The production was increased in the entire plant up to 15466 units. All these manufacturing changes bring up a better solution by $91,98 \%$. The multiplier effect is almost doubled compared to the default status for the machine operator. This is the correct strategy to use. In the last step, there is an increase in pressure on employees with an efficient production configuration. Another benefit is very small. If somebody requires a fast recipe to increase employee performance, one way exists. It often helps to precisely define the results and tasks that are required. To know what is expected of them and then check their performance results on a weekly basis. Let people just to make regular accounts of their activities. We would like to focus on the multiplier effect in the future.

\section{Acknowledgments}

This work was supported by the Ministry of Education, Youth and Sports of the Czech Republic within the National Sustainability Programme project No. LO1303 (MSMT-7778/2014) and also by the European Regional Development Fund under the project CEBIA-Tech No. CZ.1.05/2.1.00/03.0089 and also by the Internal Grant Agency of Tomas Bata University under the project No. IGA/FAI(CEBIA)/2016/033.

\section{References}

[1] Cecil-Wright, J. (1986). How the boardroom can influence warehousing costs. International Journal of Retail \& Distribution Management, 14 (3), 67-69.

[2] Segerstedt, A., Pettersson, A.I. (2012). Measurements of excellence in a supply chain. International Journal of Logistics Systems and Management, 13 (1), 65-80.

[3] Hausman, W.H., Schwarz, L.B. and Graves, S.C. (1976). Optimal storage assignment in automatic warehousing system. Management Science, 22 (6), 629-638.

[4] Muppani, V.R., Adil, G.K. and Bandyopadhyay, A. (2010). A review of methodologies for class-based storage location assignment in a warehouse. International Journal of Advanced Operations Management, 2 (3-4), $274-291$.

[5] Kovacs, A. (2011). Optimizing the Storage Assignment in a Warehouse Served by Milkrun Logistics. International Journal of Production Economics, 133 (1), 312-318.

[6] Glock, C.H. and Grosse, E.H. (2012). Storage policies and order picking strategies in U-shaped order picking systems with a movable base. International Journal of Production Research, 50 (16), 4344-4357.

[7] De Koster, R.B.M., Le-Duc, T. and Zaerpour, N. (2012). Determining the number of zones in a pick and-sort order picking system. International Journal of Production Research, 50 (3), 757-771.

[8] Bragg S. M. (2013) Inventory Management, Accounting Tools, Colorado.

[9] Waters D. (2003) Inventory Control and Management (Business), John Wiley and Sons, 2nd edition.

[10] Piasecki D. J. (2009)., Inventory Management Explained, Ops Publishing.

[11] Granville D. (2007). Excellence in Inventory Management: How to Minimise Costs and Maximise Services, Cambridge Academic; First edition.

[12] Milner C. (2015). Inventory Management: Advanced Methods for Managing Inventory within Business Systems, Kogan Page; 1 edition.

[13] Grinsted S. (2013). The Logistics and Supply Chain Toolkit: Over 90 Tools for Transport, Warehousing and Inventory Management, Kogan Page; 1 edition.

[14] Muller M. (2011). Essentials of Inventory Management, Amacom, 2nd edition.

[15] Bottani E., R. Montanari, M. Rinaldi and G. Vignali (2015). Intelligent algorithms for warehouse management. Intelligent Systems Reference Library, 87, pp. 645-667.

[16] López J. A, Mendoza A. and J. Masini (2013). A classic and effective approach to inventory management. International Journal of Industrial Engineering: Theory Applications and Practice, 20 (56), pp. 372-386.

[17] Xiao Y., Zhang R. and I. Kaku (2011). A new approach of inventory classification based on loss profit. Expert Systems with Applications, 38 (8), pp. 9382-9391.

[18] Paweł P., Marek F. and G. Paulina (2008). Using ABC Classification to determine production sequence in automotive industry, In Proceedings of 2008 World Automation Congress, WAC 2008, IEEE, pp. 1-6.

[19] Smith A.D. (2011). Inventory management and ABC analysis practices in competitive environments. International Journal of Procurement Management, 4 (4), pp. 433-454.

[20] Miculescu, M. N.; Lut, D. M. \& Miculescu, C. (2011). Current Trends of Production Cost Accounting, Annals of DAAAM for 2011 \& Proceedings of the 22nd International DAAAM Symposium, 23-26th November 2011, Vienna, Austria, Volume 22, No. 1, ISSN 1726-9679, ISBN 978-3-901509-83-4, Katalinic, B. (Ed.), pp. 0941-0942, Published by DAAAM International Vienna, Vienna

[21] Pasic, M.; Kadric, E. R. \& Bajric, H. (2010). Relationship between Inventory Investment and Forecasting and Inventory Control, Annals of DAAAM for 2010 \& Proceedings of the 21st International DAAAM Symposium, 2023rd October 2010, Zadar, Croatia, ISSN 1726-9679, ISBN 978-3-901509-73-5, Katalinic, B. (Ed.), pp. 0511-0512, Published by DAAAM International Vienna, Vienna 